\title{
Real world use of idarucizumab for dabigatran reversal in Aragón (Spain)
}

\begin{abstract}
Background: Idarucizumab is the only reversal agent specifically targeting dabigatran anticoagulation effect. Real-world evidence for idarucizumab in Spain is limited.

Objectives: To assess idarucizumab management and results according to the routine clinical practice in emergency situations in Aragon (Spain).

Methods: Observational, retrospective, multicentre study in Aragon (Spain). All patients that received idarucizumab (January 2016 - October 2019) for urgent reversal (major bleeding or emergency surgery) were included. Reversal effect was based on the activated Partial Thromboplastin Time (aPTT) in the first $24 \mathrm{~h}$.

Results: During the study period, thirty patients needed idarucizumab reversal in Aragon: $22(73.3 \%)$ emergency surgeries, $7(23.3 \%)$ major bleedings and 1 off-label use. Most patients were male $(63.3 \%)$, aged $(70.0 \% \geq 75 \mathrm{y}-\mathrm{o})$ and showed mild/moderate renal impairment $(80.0 \%)$. A high proportion of patients $(66.7 \%)$ used dabigatran $110 \mathrm{mg}$ (twice daily). Complete reversal (aPTT $\leq 40$ seconds) was shown in $70.0 \%$ of the patients (85.7\% major bleeding; $63.6 \%$ emergency surgery). Haemostasis was restored mainly in aged patients $(81 \%$ in patients $\geq 75 \mathrm{y}-0$ ), female $(81.8 \%)$ and dabigatran reduced dose users $(75.0 \%)$. Adverse events were shown in two patients $(6.7 \%)$, none of them thrombosisrelated. Since no thromboembolism was shown, according to clinical criteria, all patients could be considered as successfully reverted.
\end{abstract}

Conclusions: Idarucizumab demonstrated effective reversal of dabigatran in $\geq 70 \%$ of the emergency situations linked to anticoagulation reversal need in Aragon (Spain). The clinical use of idarucizumab was safe and conducted according to the authorized label, although it would be recommendable the development of standardized hospital protocols to guarantee an optimal drug use.

Keywords: anticoagulant drugs, antidotes, therapeutic use, evidence-based practice
Volume 13 Issue 6 - 2020

Olga Gavín,' José Manuel Calvo, ${ }^{2}$ Manuela

Dobón-Rebollo,' Irene Amarilla,' Nuria

Fernández, ${ }^{2}$ Luis Ignacio Sancho,' Isabel

Cuesta, ${ }^{3}$ Marta Villalba, ${ }^{2}$ Pedro Paul, ${ }^{4}$ Esther

Franco-García, ${ }^{5}$ Ángeles Pérez, ${ }^{6}$ Laura Lacalle $^{7}$

'Department of Hematology and Hemotherapy, Lozano-Blesa University Hospital, Spain

${ }^{2}$ Department of Hematology and Hemotherapy, Miguel Servet Hospital, Spain

${ }^{3}$ Department of Hematology and Hemotherapy, Hospital Obispo Polanco, Spain

${ }^{4}$ Department of Hematology and Hemotherapy, Hospital Comarcal de Barbastro, Spain

${ }^{5}$ Department of Hematology and Hemotherapy, Hospital Nuestra Señora de Gracia, Spain

${ }^{6}$ Department of Hematology and Hemotherapy, Hospital Royo Villanova, Spain

${ }^{7}$ Department of Hematology and Hemotherapy, Hospital San Jorge, Spain

Correspondence: Olga Gavín Sebastián, Haematology and Hemotherapy Service, Hospital Clínico Universitario Lozano Blesa, Avda. San Juan Bosco, I5, 50009 Zaragoza, Tel 9767657 00,Email ogavin@hotmail.es

Received: November 28, 2020 | Published: December 19 , 2020
Abbreviations: aPTT, activated partial thromboplastin time; PT, prothrombin time; SD, standard deviation; AEMPS, agencia española de medicamentos y productos sanitarios, DOACs, direct oral anticoagulants, VKAs, vitamin $\mathrm{K}$ antagonists

\section{Introduction}

Anticoagulation procedures have evolved significantly in the most recent years, including predictable therapeutic molecules that have allowed a more independent and autonomous management of the disease by the patient. ${ }^{1}$ Direct Oral Anticoagulants (DOACs) have represented a great advance in anticoagulation, having shown similar efficacy to traditional vitamin $\mathrm{K}$ antagonists (VKAs), although with significant advantages in terms of safety, administration comfort and response predictability. ${ }^{2}$ However, despite the advantages of DOACs, these drugs are not exempt from limitations, mainly related to the potential risk of major bleeding and high cost to healthcare systems., ${ }^{2,3}$ Regarding outcomes, the cost of DOACs could be understood as a healthcare investment, since they could provide the main benefits of VKA therapies, without their main limitations. ${ }^{3,4}$ However, major bleeding need for an appropriated and effective management, as it could lead to serious consequences for the patient's healthcare, including death. ${ }^{4,5}$

Currently, there are four DOACs available in Spain (dabigatran, rivaroxaban, apixaban and edoxaban $){ }^{6}$ showing a similar clinical profile, not differentiated through comparative studies, although with some differentiating aspects, ${ }^{7}$ such as the availability of antidotes. To date, dabigatran is the only DOAC with an authorized reversal agent available in Spain, ${ }^{6}$ idarucizumab $\left(\right.$ Praxbind $\left.^{\circledR}\right)$.

Idarucizumab is a humanized monoclonal antibody fragment that binds dabigatran with high affinity and specificity being capable to conduct to a fast reversal of the anticoagulant activity. ${ }^{8}$ The use of idarucizumab in Spain is limited to adult patients receiving dabigatran treatment and having one of the following situations: (i) emergency surgery or intervention linked to bleeding risk; (ii) life-threatening or uncontrolled bleeding. ${ }^{9}$ The possibility to have a reversal agent in case of major bleeding is a relevant clinical advantage for patient's management, ${ }^{10}$ supported by real-world data experiences from different countries. ${ }^{11-13}$ However, routine clinical practice may differ depending on the centre, country and patient profile, being necessary to define an appropriate protocol or guideline to provide a common management framework for the use of these agents at hospital level. ${ }^{14,15}$

Real-world experiences are limited, as the number of patients needing for dabigatran reversal is low and the available evidence is mainly focused on single centre experiences and ad-hoc case studies. ${ }^{13-15}$ The main study focused on idarucizumab outcomes was the RE-VECTO Surveillance Program, which included a total of 359 patients worldwide (152 in the European field). ${ }^{16}$ Currently, there is a lack of robust and common real-world data capable to provide information enough about the use of idarucizumab and the results obtained. In this regard, it is important to collect and report as much information as possible about the use of idarucizumab in routine clinical practice. Accordingly, the objective of this study was to collect 
the management, clinical data and outcome results of all patients who required idarucizumab, as reversal agent, during the time frame of the study. The results presented in this work aim to reflect the reality of the management and the results of the use of idarucizumab (Praxbind ${ }^{\mathbb{}}$ ) according to the routine clinical practice in Aragon (Spain).

\section{Methods}

\section{Study design and population}

This is a non-interventional, retrospective and multicentre study, involving all hospital healthcare centres in Aragon (Spain): Hospital Clínico Universitario Lozano Blesa (Zaragoza), Hospital Universitario Miguel Servet (Zaragoza), Hospital Royo Villanova (Zaragoza), Hospital Ernest Lluch Martin (Calatayud, Zaragoza), Hospital Comarcal Alcañiz (Teruel), Hospital de Teruel (Teruel), Hospital General San Jorge (Huesca), and Hospital de Barbastro (Huesca).

All the participant centres were invited to participate in the study and collect all the available data from patients who had been treated with idarucizumab for dabigatran reversal during the study period. Data collection was limited to the included in the clinical chart of each participant centre. From January 2016 to October 2019, all adult patients treated with dabigatran and requiring administration of idarucizumab $\left(\operatorname{Praxbind}^{\circledR}\right.$ ) according to the clinical criteria, were included in the study database.

\section{Study variables}

Main study variables were collected from the patient's clinical chart, including: socio-demographic variables (gender, age), clinical variables (weight, main diagnosis and renal function), ${ }^{17}$ treatment variables (anticoagulant drug, dose and duration, need for bleeding reversal, safety data) and laboratory tests (creatinine, activated Partial Thromboplastin Time (aPTT), Prothrombin Time (PT)). All study data was extracted from the clinical chart through a common Excel database for all participating centres, specifically designed for the study and ensuring the anonymity, confidentiality and safety protection of the reported data.

\section{Data analysis}

Due to sample limitations, all data was analysed as descriptive. The study groups were defined according to the main reason for dabigatran reversal: (i) emergency surgery, and (ii) major bleeding in non-surgical patients. Emergency surgery was defined as a multidisciplinary surgery performed for traumatic and non-traumatic acute conditions during the hospital admission. ${ }^{18}$ Major bleeding in non-surgical patients included: (i) fatal bleeding, and/or (ii) symptomatic bleeding in a critical area or organ, such as intracranial, intraspinal, intraocular, retroperitoneal, intra-articular or pericardial, or intramuscular with compartment syndrome, and/or (iii) bleeding causing an haemoglobin level decrease $\geq 20 \mathrm{~g} / \mathrm{L}$, or leading to transfusion of $\geq 2$ units of whole blood or red cells. ${ }^{19}$

Statistical analysis was performed in excel, using absolute and relative frequencies in case of discrete qualitative and quantitative variables, and average statistics, standard deviation (SD) and median (min-max values) in case of continuous quantitative variables. Idarucizumab outcomes were defined as: (i) reestablishment of the patient's haemostasis parameters and (ii) recording of safety drugrelated events. In terms of effectiveness, related to reestablishment of haemostasis parameters, complete reversal was defined as a normalization of the aPTT time within the 24 hours post idarucizumab infusion. The reference range considered for aPTT normalization was $\leq 40$ seconds. $^{20,21}$ In addition, PT time normalization was also analysed, considering PT time reduction $\leq 13.5$ seconds, 24 hours after idarucizumab infusion, ${ }^{22}$ according to the standard laboratory tests conducted by the public Healthcare Centres in Aragon and aligned with the international guidelines. ${ }^{23}$

\section{Ethics considerations}

The study was conducted according to the ethical principles of the Helsinki Declaration and the guidelines specified in the Spanish Order SAS/3470/2009 of the Agencia Española de Medicamentos $y$ Productos Sanitarios (AEMPS) for the development of studies based on human subject data. The only study data source was the clinical chart of the patients treated with idarucizumab according to the routine clinical practice of each participant centre. All the collected information was anonymized and included in a single database for statistical analysis purposes. As data was collected retrospectively and completely dissociated from personal identification, no information consent was considered as needed for study purposes.

\section{Results}

Between January 2016 and October 2019, a total of 30 patients were treated with idarucizumab $\left(\right.$ Praxbind $^{\mathbb{Q}}$ ) in the hospital centres of Aragon (Spain). Most patients receiving idarucizumab (Praxbind ${ }^{\circledR}$ ) for dabigatran reversal were male $(63.3 \%)$, and the mean age (SD) was 77.9 (13.4) years, ranging from 39 to 93 years (Table 1). Atrial fibrillation (AF) was the main indication for dabigatran use in all the included patients, and the most frequently used dose was $110 \mathrm{mg}$ twice daily $(66.7 \%$ patients). Most of the included patients $(80.0 \%)$ showed mild or moderate renal impairment. Only one of the included patients showed renal failure (creatinine clearance $<30 \mathrm{~mL} / \mathrm{min}$ ) (Table 1).

Table I Baseline socio-demographic and clinical profile of the patients that needed for idarucizumab(Praxbind $\left.{ }^{\circledR}\right)$ in $A r a g o n(S p a i n)$

\begin{tabular}{llll}
\hline & Emergency Surgery $(\mathbf{n}=22)$ & Major bleeding $(\mathbf{n}=\mathbf{7})$ & Total $(\mathbf{n = 3 0})$ \\
\hline Gender(male); $(\%)$ & $16(72.7)$ & $3(42.9)$ & $19(63.3)$ \\
Age(years); mean(SD) & $76.5(14.7)$ & $83.0(8.7)$ & $77.9(13.4)$ \\
Age(years); $n(\%)$ & & & $5(16.7)$ \\
$\leq 65$ y-o & $4(18.2)$ & $1(14.3)$ & $4(13.3)$ \\
$66-74$ y-o & $3(13.6)$ & $0(0.0)$ & $21(70.0)$ \\
$\geq 75$ y-o & $15(68.2)$ & $6(85.7)$ & $76.7(21.2)$ \\
Weight(Kg); mean(SD) & $78.4(42.9)$ & $70.8(38.0)$ & $66.5(23.6)$ \\
Renal function(CrCl;mL/min); mean(SD) & $65.5(21.2)$ & $60.7(19.9)$ & \\
\hline
\end{tabular}


Table continued...

\begin{tabular}{|c|c|c|c|}
\hline & Emergency Surgery $(n=22)$ & Major bleeding $(n=7)$ & Total $(n=30)$ \\
\hline Normal( $\geq 90 \mathrm{~mL} / \mathrm{min})$ & $3(13.6)$ & $\mathrm{I}(14.3)$ & $5(16.7)$ \\
\hline Mild renal impairment $(60-<90 \mathrm{~mL} / \mathrm{min})$ & $\mathrm{II}(50.0)$ & $2(28.6)$ & $13(43.3)$ \\
\hline Moderate renal impairment $(30-<60 \mathrm{~mL} / \mathrm{min})$ & $7(31.8)$ & $4(57.1)$ & II(36.7) \\
\hline Severe renal impairment $(<30 \mathrm{~mL} / \mathrm{min})$ & $\mathrm{I}(4.5)$ & $0(0.0)$ & $\mathrm{I}(3.3)$ \\
\hline Creatinine level(mg/dL); mean(SD) & $2.0(2.7)$ & $2.3(3.0)$ & $2.0(2.7)$ \\
\hline Dabigatran initiation(months); mean(SD) & $56.6(36.7)$ & $44.3(34.4)$ & $55.3(34.9)$ \\
\hline \multicolumn{4}{|l|}{ Dabigatran dose(twice daily);n(\%) } \\
\hline Standard dose(150 mg) & $7(31.8)$ & $2(28.6)$ & $10(33.3)$ \\
\hline Reduced dose(I 10 mg) & $15(68.2)$ & $5(7 \mid .4)$ & $20(66.7)$ \\
\hline
\end{tabular}

The main reasons for using idarucizumab $\left(\right.$ Praxbind $\left.^{\circledR}\right)$ were those included in the marketing authorization: emergency surgery $(73.3 \%$ of the patients), and major bleeding (23.3\%). Only one patient received the reversal agent for another reason (off-label), such as a suspected stroke that was ultimately identified as a drug overdose.
The most frequent emergency surgeries needing for reversal anticoagulation were mainly those of abdominal location (mainly, cholecystectomy or laparotomy). Vascular surgery was also frequently reported as a need for dabigatran reversal (Figure 1). Regarding major bleeding, the most frequently reported location was brain, followed by abdominal bleeding (Figure 1).

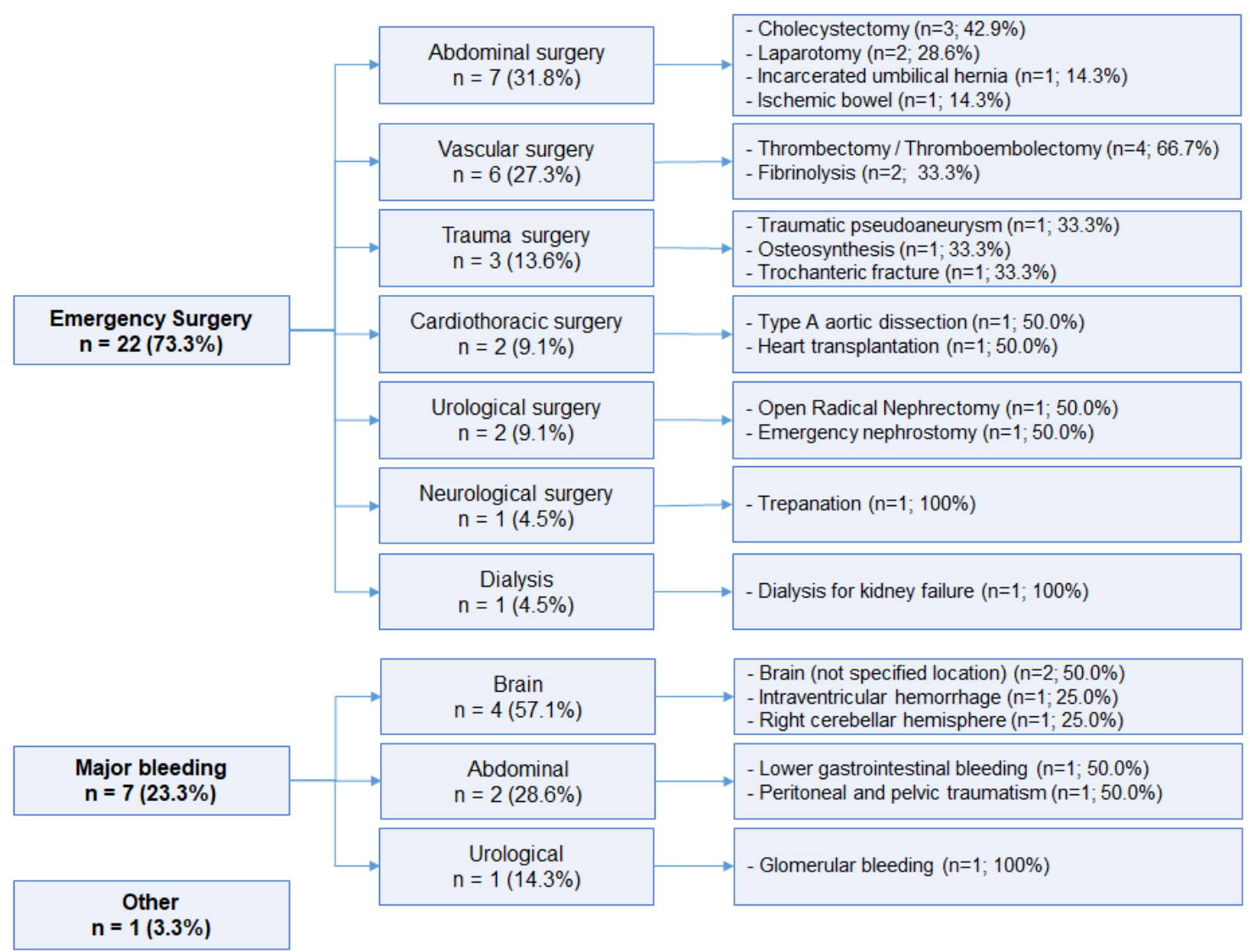

Figure I Categorization of the patients receiving idarucizumab (Praxbind ${ }^{\circledR}$ ) according to the main reason for dabigatran reversal need.

The analysis of the coagulation parameters (Table 2) indicated that, prior to idarucizumab (Praxbind $\left.{ }^{\circledR}\right)$ infusion, 17 patients $(56.7 \%)$ showed a prolonged activated partial thromboplastin time (aPTT), increasing to 19 patients $(63.3 \%)$ according to prothrombin time (PT). Twenty-four hours after reversal agent infusion, the number of patients with prolonged aPTT or PT was reduced to 7 (23.3\%) and $16(53.3 \%)$, respectively (Table 2$)$. Based on aPTT normalization,
24 hours after idarucizumab administration, successful reversal was achieved in $70.0 \%(\mathrm{n}=21)$ of all study patients. This normalization of the coagulation parameters was irregular depending on the main reason considered for reversal need. Most of the patients receiving idarucizumab (Praxbind ${ }^{\circledR}$ ) for major bleeding $(85.7 \%)$ achieved aPTT normalization, in contrast to patients receiving the reversal agent for emergency surgery reasons $(63.6 \%$; Table 2$)$. 
Table 2 Coagulation parameters of the patients that received idarucizumab (Praxbind®) according to the routine clinical practice in Aragon(Spain)

\begin{tabular}{|c|c|c|c|}
\hline & Emergency Surgery $(n=22)$ & Major bleeding(n=7) & Total $(n=30)$ \\
\hline \multicolumn{4}{|l|}{ aPTT value(seconds); mean(SD) } \\
\hline Pre-idarucizumab value & $44.0(19.9)$ & $51.0(13.6)$ & $45.3(18.4)$ \\
\hline Post-idarucizumab value & $40.3(26.0)$ & $42.0(37.1)$ & $40.5(28.0)$ \\
\hline \multicolumn{4}{|l|}{ aPTT pre-idarucizumab; n(\%) } \\
\hline Normal & II (50.0) & $\mathrm{I}(14.3)$ & $13(43.3)$ \\
\hline Prolonged & II (50.0) & $6(85.7)$ & $17(56.7)$ \\
\hline \multicolumn{4}{|l|}{ aPTT post-idarucizumab; n(\%) } \\
\hline Normal & $14(63.6)$ & $6(85.7)$ & $2 I(70.0)$ \\
\hline Prolonged & $6(27.3)$ & $\mathrm{I}(14.3)$ & $7(23.3)$ \\
\hline Missing & $2(9.1)$ & $0(0.0)$ & $2(6.7)$ \\
\hline \multicolumn{4}{|l|}{ PT value(seconds); mean(SD) } \\
\hline Pre-idarucizumab value & $16.6(6.0)$ & $16.9(5.3)$ & $16.6(5.7)$ \\
\hline Post-idarucizumab value & $17.0(13.1)$ & $22.9(25.6)$ & $18.2(16.1)$ \\
\hline \multicolumn{4}{|l|}{ PT pre-idarucizumab; n(\%) } \\
\hline Normal & $5(22.7)$ & $\mathrm{I}(14.3)$ & $7(23.3)$ \\
\hline Prolonged & $14(63.6)$ & $5(71.4)$ & $19(63.3)$ \\
\hline Missing & $3(13.6)$ & $\mathrm{I}(14.3)$ & $4(13.3)$ \\
\hline \multicolumn{4}{|l|}{ PT post-idarucizumab; $\mathbf{n ( \% )}$} \\
\hline Normal & $8(36.4)$ & $3(42.9)$ & II (36.7) \\
\hline Prolonged & $12(54.5)$ & $3(42.9)$ & $16(53.3)$ \\
\hline Missing & $2(9.1)$ & $\mathrm{I}(14.3)$ & $3(10.0)$ \\
\hline Anticoagulation change after reversal; $n(\%)$ & $8(44.4)$ & $3(75.0)$ & II(47.8) \\
\hline VKA & $3(37.5)$ & $0(0.0)$ & $3(27.3)$ \\
\hline Other DOAC & $2(25.0)$ & $2(66.7)$ & $4(36.4)$ \\
\hline Antiaggregation & $\mathrm{I}(12.5)$ & $0(0.0)$ & $\mathrm{I}(9.1)$ \\
\hline None & $2(25.0)$ & $I(33.3)$ & $3(27.3)$ \\
\hline
\end{tabular}

aPTT: activated Partial Thromboplastin Time; PT: Prothrombin Time

Four of the seven patients failing to complete reversal with idarucizumab $\left(\right.$ Praxbind $^{\circledR}$ ) showed aPTT values lower than 43 seconds (Table 3), and two of these patients showed normalisation criteria according to the PT value ( $\leq 13.5$ seconds). Complete clinical evaluation for these patients was not available, not being possible the individual assessment of other parameters potentially related to an effective haemostasis. Based on aPTT and considering other variables beyond reversal main need, such as age, gender or dabigatran dose, it was shown that the highest proportion of patients achieving coagulation normalization was formed by aged patients (Figure 2 ), female (Figure 3), and patients treated with the reduced dose of dabigatran (110mg twice daily) (Figure 4).

Table 3 Socio-demographic and clinical variables of the patients failing to haemostasis normalization(aPTT $\leq 40$ seconds)

\begin{tabular}{|c|c|c|c|c|c|c|c|c|c|}
\hline Gender & $\begin{array}{l}\text { Age } \\
\text { (years) }\end{array}$ & $\begin{array}{l}\mathrm{CrCl} \\
(\mathrm{mL} / \mathrm{min})\end{array}$ & $\begin{array}{l}\text { Dabigatran } \\
\text { dose(mg) }\end{array}$ & $\begin{array}{l}\text { Reversal } \\
\text { need }\end{array}$ & $\begin{array}{l}\text { Type of surgeryl } \\
\text { bleeding }\end{array}$ & $\begin{array}{l}\text { aPTT (pre- } \\
\text { idarucizumab) }\end{array}$ & $\begin{array}{l}\text { aPTT (post- } \\
\text { idarucizumab) }\end{array}$ & $\begin{array}{l}\text { PT (pre- } \\
\text { idarucizumab) }\end{array}$ & $\begin{array}{l}\text { PT(post- } \\
\text { idarucizumab) }\end{array}$ \\
\hline Male & 70 & 69.1 & 150 & $\begin{array}{l}\text { Emergency } \\
\text { Surgery }\end{array}$ & $\begin{array}{l}\text { Type A aortic } \\
\text { dissection }\end{array}$ & 45.6 & 98.9 & 11.7 & 14.1 \\
\hline Male & 46 & 40.0 & 110 & $\begin{array}{l}\text { Emergency } \\
\text { Surgery }\end{array}$ & $\begin{array}{l}\text { Heart } \\
\text { transplantation }\end{array}$ & 57.6 & 40.2 & 16.6 & 11.9 \\
\hline Male & 71 & 97.7 & 110 & $\begin{array}{l}\text { Emergency } \\
\text { Surgery }\end{array}$ & Dialysis & 113.4 & 41.1 & 38.4 & 13 \\
\hline Female & 83 & 85.0 & 110 & $\begin{array}{l}\text { Emergency } \\
\text { Surgery }\end{array}$ & $\begin{array}{l}\text { Trochanteric } \\
\text { fracture }\end{array}$ & 47.4 & 42.3 & 15.7 & 13.9 \\
\hline Female & 93 & 57.0 & 110 & $\begin{array}{l}\text { Emergency } \\
\text { Surgery }\end{array}$ & $\begin{array}{l}\text { Abdominal } \\
\text { (Incarcerated } \\
\text { umbilical hernia) }\end{array}$ & 75.9 & 127.6 & 22.3 & 72.1 \\
\hline Male & 54 & 82.0 & 150 & $\begin{array}{l}\text { Emergency } \\
\text { Surgery }\end{array}$ & Thrombectomy & 32.6 & 41.8 & - & 17.7 \\
\hline
\end{tabular}




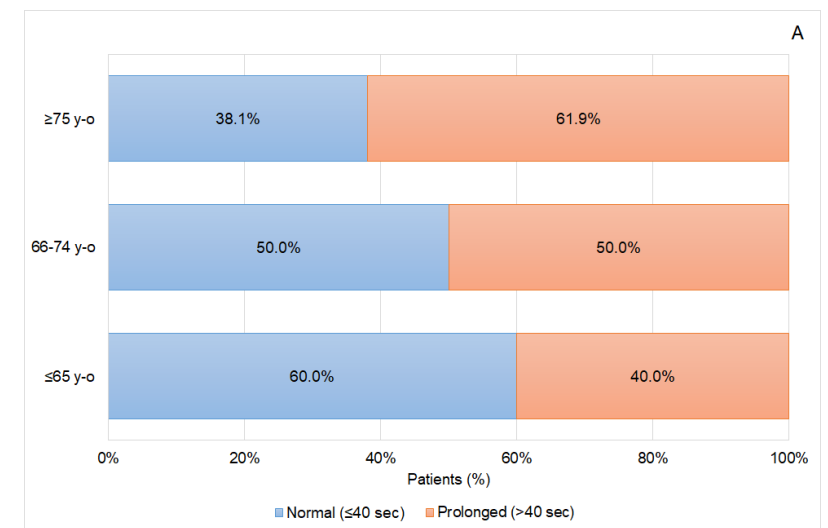

Figure 2A

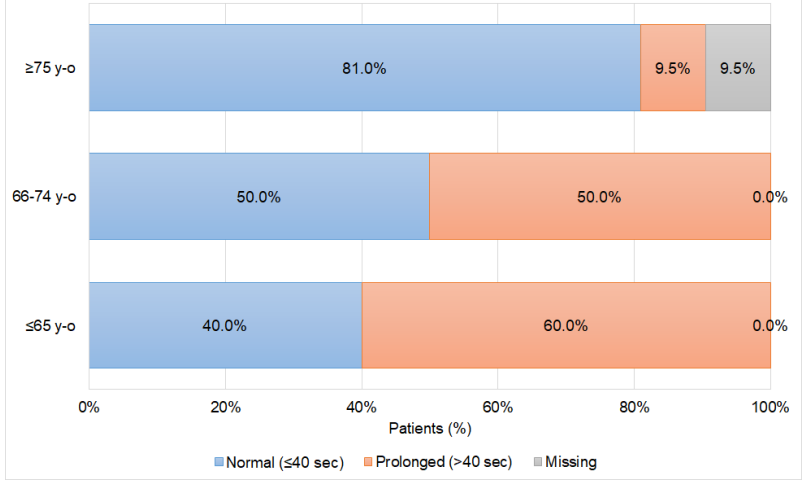

Figure 2B

Figure 2 Coagulation status of the patients based on the activated Partial Thromboplastin (aPTT) time according to patients' age (A) prior to idarucizumab infusion, and (B) 24 hours after idarucizumab infusion.

In terms of safety, after idarucizumab (Praxbind ${ }^{\circledR}$ ) infusion, adverse events were reported in two patients $(6.7 \%)$, being identified as acute renal failure and epistaxis, respectively. No post-infusion thrombotic events were reported. Seven of the 30 patients treated with idarucizumab (Praxbind $\left.{ }^{\circledR}\right)$ died $(23.3 \%)$, being the main causes: septic shock $(n=1)$, multiorgan failure $(n=2)$, metastatic bladder and acute renal failure $(n=1)$. The cause of death was not registered in three of these patients. After anticoagulation reversal, anticoagulation strategy was modified in 11 patients (47.8\%), mainly to other DOAC $(36.4 \%)$, especially in case of need for reversal linked to a major bleeding, or to VKA $(27.3 \%)$, mostly in surgery patients (Table 2 ).
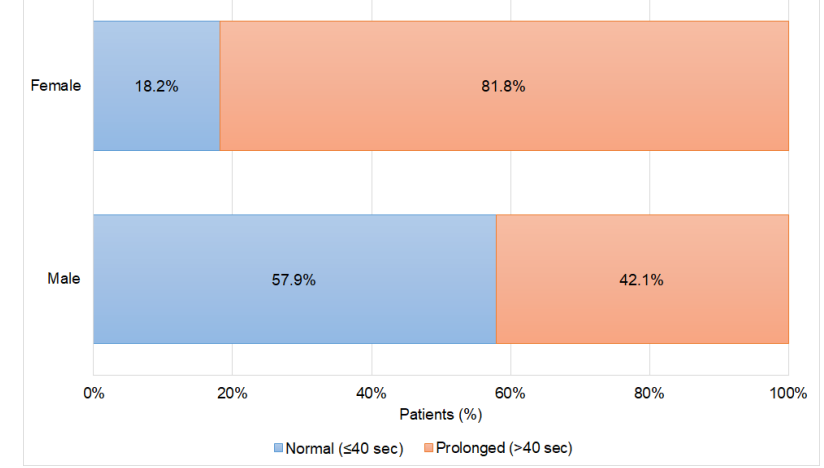

Figure 3A

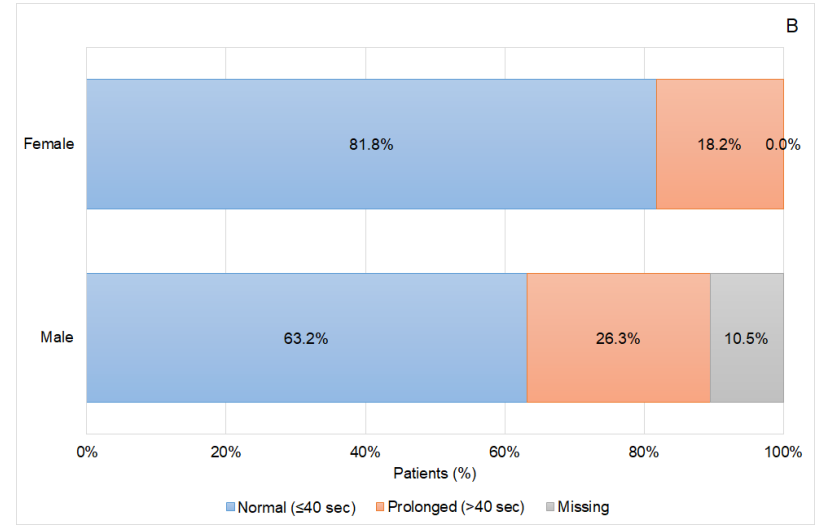

Figure 3B

Figure 3 Coagulation status of the patients based on the activated Partial Thromboplastin (aPTT) time according to patients' gender (A) prior to idarucizumab infusion, and (B) 24 hours after idarucizumab infusion.

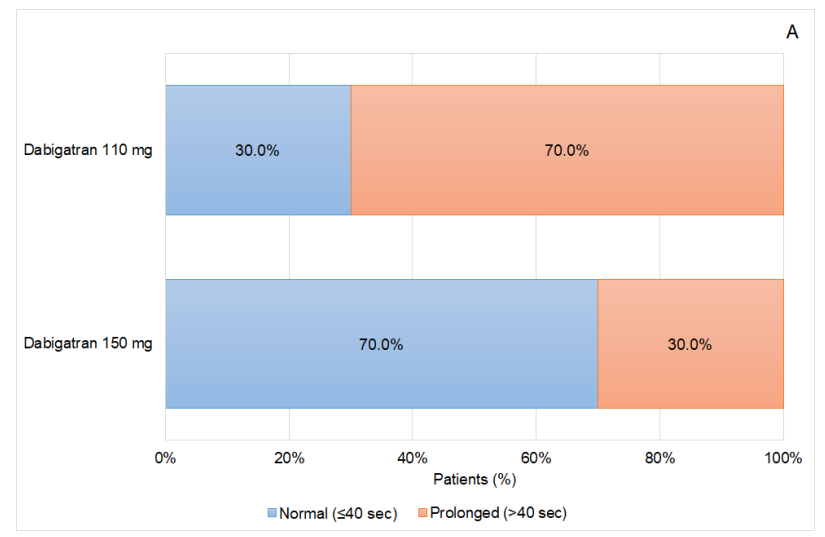

Figure 4A

B
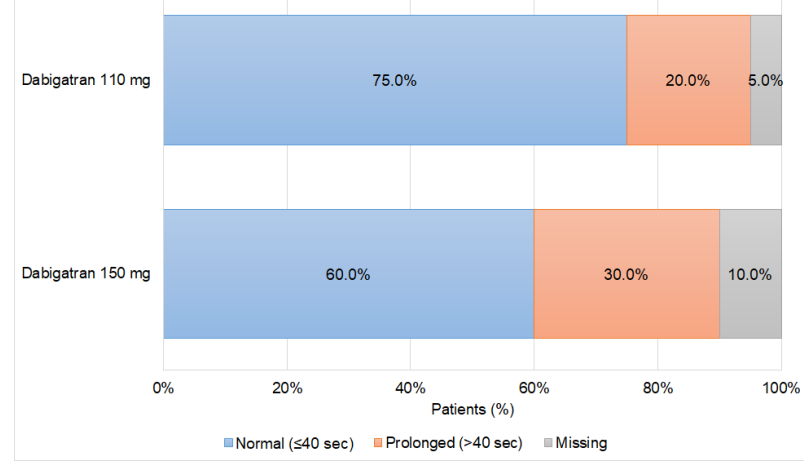

\section{Figure 4B}

Figure 4 Coagulation status of the patients based on the activated Partial Thromboplastin (aPTT) time according to the dabigatran dose used (A) prior to idarucizumab infusion, and (B) 24 hours after idarucizumab infusion.

\section{Discussion}

Dabigatran is a DOAC commonly used in Spain for stroke prevention in patients with $\mathrm{AF}$ and for the prevention and management of venous thromboembolism. ${ }^{6,24}$ Similar to other anticoagulation therapies, dabigatran treatment could be linked to serious bleeding risks related to emergency medical procedures. The presence of bleeding 
needs for reversion, through reversal agents, when available. In this regard, idarucizumab $\left(\operatorname{Praxbind}^{\mathbb{}}{ }^{\text {) }}\right.$ is the only specific agent available for dabigatran anticoagulation reversal ${ }^{10}$ in routine clinical practice. The results of the prospective study RE-VERSE AD ("Reversal Effects of Idarucizumab on Active Dabigatran) demonstrated the fast and total reversal of dabigatran effect provided by idarucizumab administration, ${ }^{10}$ being especially useful in emergency situations.

According to the routine healthcare practice in Aragon, the complete reversal effect of idarucizumab $\left(\right.$ Praxbind $\left.^{\mathbb{Q}}\right)$, based on aPTT normalization in the 24 hours post-infusion, would be achieved in $70.0 \%$ of the study patients (up to $85.7 \%$ in case of major bleeding). This percentage of successful anticoagulant reversion agrees with the reversal effect showed by idarucizumab in both, clinical trials ${ }^{25}$ and real-world data studies. ${ }^{11,13,26}$

According to the ISTH (International Society on Thrombosis and Haemostasis), ${ }^{27}$ the management of haemostasis in patients with a major bleeding should consider additional factors to aPTT to be considered as effective, depending on bleeding type and location. Similarly, for surgery patients, beyond the aPTT value, it should be considered the time needed for the surgery initiation and the absence of thromboembolic events after surgery procedure. ${ }^{28,29}$ Therefore, considering these other factors beyond the laboratory coagulation parameters, and based on the absence of thromboembolic events registered after idarucizumab (Praxbind ${ }^{\mathbb{R}}$ ) administration, it could be considered that the effective management of the haemostasis would be achieved in close to the total of patients included in our registry.

In Aragon, the main need for dabigatran reversal with idarucizumab $\left(\right.$ Praxbind $\left.^{\mathbb{}}\right)$ was shown in emergency surgeries, representing the $73.3 \%$ of the patients included in the study. Major bleeding reversal was only needed in seven of the thirty patients included (23.3\%). Both, emergency surgery and major bleeding were the most frequent reasons for an urgent and complete anticoagulation reversal need. ${ }^{30}$ Although for dabigatran treated patients, idarucizumab (Praxbind ${ }^{\mathbb{R}}$ ) is the only reversal agent available, and the management guidelines in Spain are well stablished, ${ }^{9}$ the specific protocol used for drug administration could differ among healthcare centres, which could conduct to different outcome results. The participant investigators including patients in the study were, all of them, experienced in the management of DOAC related bleeding, and, more specifically in dabigatran reversal with idarucizumab $\left(\right.$ Praxbind $\left.^{\mathbb{}}\right)$, for major bleeding and emergency surgery situations.

In agreement with prior real-world experiences, ${ }^{11,13,16,26}$ most of the patients included in the study were aged patients, over 75 years old, and even older than 75 years in case of patients needing for major bleeding reversal. ${ }^{26}$ The age of the patients that needed dabigatran anticoagulation reversal could be the main cause for the high percentage of patients receiving the reduced dose of this DOAC. The most common situation needing for bleeding reversal was an emergency surgery, which may or may not be related to a major bleeding. After reversal, about half of the patients changed their anticoagulation strategy (up to $75.0 \%$ considering patients with major bleeding).

According to the main clinical recommendations for anticoagulation reversal, ${ }^{30,31}$ the main goal for a complete reversal of the anticoagulant effect is the normalization of the haemostasis in the shortest possible time, in absence of thromboembolic events. Since dabigatran was the DOAC considered for this study, and PT is generally not a recommended test for this DOAC, prolonged aPTT was the variable considered as reference for anticoagulation reversal assessment. ${ }^{30}$ Normalization of aPTT 24 hours after idarucizumab (Praxbind ${ }^{\circledR}$ ) infusion was found in $70 \%$ of the study patients, a slightly lower percentage than the reported in the main idarucizumab studies. ${ }^{11,13,26}$ This difference could be related to different factors, such as: (i) different reversal administration protocols for idarucizumab among centres, (ii) different patient profile and (iii) different measurement moments for aPTT (considered as 24 hours after idarucizumab infusion, although not linked to a predefined protocol). Additionally, there are different recommendations that focus the anticoagulation reversal effect on other additional parameters beyond those of the laboratory (aPTT). ${ }^{27-}$ ${ }^{29}$ This is the case of the clinical criteria for bleeding activity in case of major bleeding, ${ }^{27}$ or the need for a quick intervention in case of an emergency surgery, as well as the absence of thromboembolic events after the administration of the reversal agent. ${ }^{28,29}$ Considering these parameters, given that no thromboembolic events were evident in any patient, the administration of idarucizumab would have been successful in all cases.

Analysing the data obtained in greater detail, some interesting effects on the response based on the aPTT values were observed in the patients treated with idarucizumab according to routine clinical practice in Aragon. On one hand, it was shown that aPTT normalization was greater as the age of the patients included in the study increased, ranging from $40.0 \%$ in patients $\leq 65$ years to $81.0 \%$ in patients older than 80 years. On the other hand, related to age effect, female patients were those showing a better reversal effect than male, achieving aPTT normalization in $81.8 \%$ of the patients, and coinciding in that female patients were also the oldest patients. Again, related to age, apart from other factors, those patients who were treated with a reduced dose of dabigatran $(110 \mathrm{mg})$ presented a higher proportion of aPTT normalization $(75.0 \%)$ than those patients treated with the high dose $(150 \mathrm{mg})$ of this anticoagulant drug $(60.0 \%)$. The relation of the age and the reversal effect is not well defined and further analysis should be conducted in this regard.

Regardless of the patient profile considered, the use of idarucizumab provides a crucial tool for the management of anticoagulation in patients who need an emergency procedure, for either major bleeding, or emergency surgery. Response variability reflects the different healthcare realities involving the emergency management of anticoagulated patients that could have different needs at different times and that must be adequately addressed through standardized protocols.

The results of the study showed that the current management of an emergency situation for anticoagulated patients in Aragon is being conducted aligned with the real-world data available, and according to the main recommendations available for these patients and situations. ${ }^{9}$ In all cases, the use of idarucizumab was conducted according to the authorized label in Spain, ${ }^{6}$ resulting in a useful tool for an effective reversal anticoagulation in routine clinical practice, with an acceptable safety profile and without evidence of post-infusion thrombotic events.

The main limitation of the study presented corresponds to the methodology used for data collection, based on the direct registry of the routine clinical practice of each participant centre for the management of anticoagulation reversal in emergency situations. The routine clinical practice could be affected by different healthcare protocols, different patient evaluation methods and timings, as well as different data collection variables, conducting to potential information lacks, understood as missing data for analysis purposes. However, all the data collected also reflects the standard practice in case of 
an emergency need and includes the variability due to the available healthcare resources that could also affect the routine procedures for these patients. Therefore, the results presented are the most accurate description of the real-world practice regarding the management of anticoagulation reversal in emergency situations in Aragon, and probably in Spain.

\section{Conclusions}

The possibility to have a specific reversal agent is an important advantage for the clinical management of anticoagulated patients in routine clinical practice, especially in life-threatening emergency situations. The results collected from the idarucizumab experience in different healthcare centres in Aragon, evidenced the response predictability for this reversal agent, showing a fast and complete anticoagulant reversal for most of the target patients, being completed with an excellent safety profile, with no evidence of thromboembolism post-infusion. Although the positive clinical results observed in our registry, the proper use of idarucizumab $\left(\right.$ Praxbind $\left.^{\circledR}\right)$ need for healthcare staff experienced enough in anticoagulation management, as well as for a multidisciplinary approach, since several healthcare professionals are involved in these emergency situations. Therefore, the development and implementation of multidisciplinary protocols at hospital level, as well as standardized systems for reversal effect evaluation are necessary to achieve optimal idarucizumab results in the approved clinical indications.

\section{Acknowledgements}

The authors want to acknowledge the participation of the all the healthcare centres in Aragon and the data collection effort conducted by the investigators of each of the participant centers where idarucizumab patients were identified.

The study has been sponsored by the Sociedad Aragonesa de Hematología y Hemoterapia (SAHH). Medical writing assistance has been supported by IQVIA and the financial support has been provided by Boehringer Ingelheim. Boehringer Ingelheim had the opportunity to check the data used in this manuscript just for factual accuracy.

\section{Conflicts of interest}

The rest of the authors declare do not have conflicts of interest.

\section{Author contribution}

The study was designed and coordinated by the main authors, led by Dr. O. Gavín. All the study authors were actively involved in patients' identification and data collection. All of them have been also actively involved in data analysis review and interpretation. Although medical writing tasks have been conducted by IQVIA Information S.A., all the authors have contributed in the text review and discussion/ conclusions development.

\section{Funding}

Sociedad Aragonesa de Hematología y Hemoterapia (SAHH), sponsored by Boehringer Ingelheim Spain.

\section{References}

1. Franchini M, Liumbruno GM, Bonfanti B, et al. The evolution of anticoagulant therapy. Blood Transfuse. 2016;14(2):175-184.

2. Mekaj YH, Mekaj AY, Duci SB, et al. New oral anticoagulants: their advantages and disadvantages compared with vitamin $\mathrm{K}$ antagonists in the prevention and treatment of patients with thromboembolic events. Ther Clin Risk Manag. 2015;11:967-77.

3. Kaplan RS, Helmers RS, Jaeger TM, et al. Time--Driven Activity-Based Cost Analysis for Outpatient Anticoagulation Therapy: Direct Costs in a Primary Care Setting with Optimal Performance. J Med Econ. 2019;22(5):471-477.

4. Xu Y, Schulman S, Dowlatshahi D, et al. Direct Oral Anticoagulant- or Warfarin-Related Major Bleeding: Characteristics, Reversal Strategies, and Outcomes From a Multicenter Observational Study. Chest. 2017;152(1):81-91.

5. Caldeira D, Barra M, Ferreira A, et al. Systematic review with metaanalysis: the risk of major gastrointestinal bleeding with non-vitamin $\mathrm{K}$ antagonist oral anticoagulants. Aliment Pharmacol Ther. 2015;42(1112):1239-1249.

6. European Medicines Agency (EMA). Consulted in June 2020. Available at:https:/www.ema.europa.eu/en

7. Paravattil B, Elewa H. Approaches to direct oral anticoagulant selection in practice. J Cardiovasc Pharmacol Ther. 2018;1074248418793137.

8. Finks SW, Rogers KC. Idarucizumab (Praxbind): the first reversal agent for a direct oral anticoagulant. Am J Med. 2017;130(5):e195-e197.

9. Informe de Posicionamiento Terapéutico de idarucizumab (Praxbind $®)$ como antídoto especifico para revertir el efecto anticoagulante de dabigatrán en situaciones de urgencia. Informe de Posicionamiento Terapéutico (IPT). Ministerio de Sanidad, Servicios Sociales e Igualdad. Agencia Española del Medicamento y Productos Sanitarios. Consulted on June 2020. Available at: https://www.aemps.gob.es/ medicamentosUsoHumano/informesPublicos/docs/IPT-idarucizumabPraxbind-anticoagulantes-orales.pdf

10. Pollack CV, Reilly PA, Ryn JV, et al. Idarucizumab for dabigatran reversal—full cohort analysis. N Engl J Med. 2017;377(5):431-441.

11. Tsai LK, Lin HJ, Chua SK, et al. Real-World Experience with Idarucizumab to Reverse Anticoagulant Effect in Dabigatran-Treated Patients: Report of 11 Cases from Taiwan. J Stroke Cerebrovasc Dis. 2018;7(2):e27-e33.

12. Vosko MR, Bocksrucker C, Drwiła R, et al. Real-life experience with the specific reversal agent idarucizumab for the management of emergency situations in dabigatran-treated patients: a series of 11 cases. J Thromb Thrombolysis. 2017;43(3):306-317.

13. Escobar C, Divisón JA. Idarucizumab and dabigatran. RE-VERSE AD study data. Family Medicine. SEMERGEN. 2016;42(5):327-328.

14. Huisman MV, Fanikos J. Idarucizumab and factor Xa reversal agents: role in hospital guidelines and protocols. Am J Med. 2016;129(11):S89S96.

15. Ageno W, Büller HR, Falanga A, et al. Managing reversal of direct oral anticoagulants in emergency situations. Thromb Haemost. 2016;116(6):1003-1010.

16. Fanikos J, Murwin D, Gruenenfelder F, et al. Global Use of Idarucizumab in Clinical Practice: Outcomes of the RE-VECTO Surveillance Program. Thromb Haemost. 2020;120(1):27-35.

17. Guideline on the evaluation of the pharmacokinetics of medicinal products in patients with decreased renal function. European Medicines Agency (EMA). 2020.

18. Coccolini F, Kluger Y, Ansaloni L, et al. WSES worldwide emergency general surgery formation and evaluation project. World J Emerg Surg. 2018;13(1):13.

19. Schulman S, Angerås U, Bergqvist D, et al. Definition of major bleeding in clinical investigations of antihemostatic medicinal products in nonsurgical patients. J Thromb Haemost. 2010;8(1):202-204. 
20. Berrouschot J, Stoll A, Hogh T, et al. Intravenous Thrombolysis with Recombinant Tissue-Type Plasminogen Activator in a Stroke Patient Receiving Dabigatran Anticoagulant After Antagonization With Idarucizumab. Stroke. 2016;47(7):1936-1938.

21. Korber MK, langer $\mathrm{K}$, Ziemer S, et al. Measurement and reversal of prophylactic and therapeutic peak levels of rivaroxaban: an in vitro study. Clin Appl Thromb Hemost. 2014;20(7):735-740.

22. Davidson JC, Rahim S, Hanks SE, et al. Society of Interventional Radiology Consensus Guidelines for the Periprocedural Management of Thrombotic and Bleeding Risk in Patients Undergoing Percutaneous Image-Guided Interventions-Part II: Recommendations: Endorsed by the Canadian Association for Interventional Radiology and the Cardiovascular and Interventional Radiological Society of Europe. $J$ Vasc Interv Radiol. 2019;30(8):1168-1184.e1.

23. Castellone DD. Establishing reference intervals in the coagulation laboratory. Int J Lab Hematol. 2017;39 Suppl 1:121-127.

24. Criterios y recomendaciones generales para el uso de los anticoagulantes orales directos (ACOD) en la prevención del ictus y la embolia sistémica en pacientes con fibrilación auricular no valvular. Informe de Posicionamiento Terapéutico (IPT). Ministerio de Sanidad, Servicios Sociales e Igualdad. Agencia Española del Medicamento y Productos Sanitarios. Consulted on June 2020. Available at: https:// www.aemps.gob.es/medicamentosUsoHumano/informesPublicos/docs/ criterios-anticoagulantes-orales.pdf
25. Pollack CV, Reilly PA, Eikelboom G, et al. Idarucizumab for Dabigatran Reversal. N Engl J Med. 2015;373:511-520.

26. Sheikh-Taha M. Idarucizumab for Reversal of Dabigatran: Single-Center Real-World Experience. Am J Cardiovasc Drugs. 2019;19(1):59-64.

27. Khorsand N, Majeed A, Sarode R, et al. Assessment of effectiveness of major bleeding management: proposed definitions for effective hemostasis: communication from the SSC of the ISTH. J Thromb Haemost. 2016;14(1):211-214.

28. Chou $\mathrm{CH}, \mathrm{Wu} \mathrm{YT}, \mathrm{Fu} \mathrm{CY}$, et al. Hemostasis as soon as possible? The role of the time to angioembolization in the management of pelvic fracture. World J Emerg Surg. 2019;14:28.

29. Piran S, Gabriel C, Schulman S. Prothrombin complex concentrate for reversal of direct factor Xa inhibitors prior to emergency surgery or invasive procedure: a retrospective study. J Thromb Thrombolysis. 2018;45(4):486-495.

30. Ruff CT, Giugliano RP, Antman EM, Management of Bleeding With Non-Vitamin K Antagonist Oral Anticoagulants in the Era of Specific Reversal Agents. Circulation. 2016;134(3):248-261.

31. Christensen H, Cordonnier C, Korv J, et al. European Stroke Organization Guideline on Reversal of Oral Anticoagulants in Acute Intracerebral Haemorrhage. Eur Stroke J. 2019;4(4):294-306. 